\title{
Fatores protetores e de risco para depresão da mulher após o aborto
}

\author{
Protection and risk factors for women's depression after abortion \\ Factores protectores y de riesgo para la depresión de mujeres después del aborto
}

\section{Mariana Gondim Mariutti', Antonia Regina Ferreira Furegato'}

'Universidade de São Paulo. Escola de Enfermagem de Ribeirão Preto, Pós-Graduação em Enfermagem PsiQuiátrica. Ribeirão Preto, SP

Submissão: 12/12/2008

Aprovação: $08 / 02 / 2010$

\section{RESUMO}

Objetivou-se identificar fatores de risco e proteção para depressão em decorrência do abortamento. Metodologia Qualitativa com depoimentos de 13 mulheres. Os discursos foram analisados e possibilitaram a construção de duas categorias temáticas: fatores de risco e protetores. Os fatores de risco estão associados à precárias condições sócio-econômicas e afetivas; drogas; prostituição; falta de apoio social e familiar; violência. Nos fatores protetores observam-se presença de condições sócio-econômicas favoráveis à criação dos filhos; apoio familiar (especialmente do companheiro) e social; profissão e trabalho. O reconhecimento desses aspectos abre caminhos para dar melhores cuidados às mulheres em abortamento.

Descritores: Saúde mental; Mulher; Aborto.

\section{ABSTRACT}

This Qualitative study aimed to identify risk and protection factors for depression caused by abortion; statements of 13 women were analyzed. Their reports were analyzed and enabled the construction of two thematic categories: risk and protection factors. The risk factors are associated to the precarious socio-economic and affective conditions; drugs; prostitution; lack of family and social support; violence. Socio-economic conditions favorable to raising children; social and family support (especially from partner); profession and work were observed as protection factors. The recognition of these aspects open ways for improving care to women who had abortion. Key words: Mental health; Women; Abortion.

\section{RESUMEN}

Estudio cualitativo Que tuvo como objetivo identificar factores de riesgo y protección para depresión causada por el abortamiento. Declaraciones de 13 mujeres fueron analizadas y posibilitaron la construcción de dos categorías temáticas: factores de riesgo y protectores. Los factores de riesgo están asociados a las precarias condiciones socio-económicas y afectivas; drogas; prostitución; falta de apoyo social y familiar; violencia. En los factores protectores se observó la presencia de condiciones socio-económicas favorables a la creación de los hijos; apoyo social y familiar (especialmente del compañero); profesión y trabajo. El reconocimiento de esos aspectos abre caminos para dar mejor atención a las mujeres en abortamiento.

Descriptores: Salud mental; Mujeres; Aborto. 


\section{INTRODUÇÃO}

O aborto é definido clinicamente como a interrupção da gravidez ou expulsão do produto da concepção antes Que o feto seja viável ( $22^{\text {a }}$ semana) ou, se a idade gestacional for desconhecida, com o produto da concepção pesando menos de 500 gramas ou medindo menos de 16 centímetros $^{(1)}$.

É um tema polêmico, cuja prática esteve em todas as épocas, podendo ser abordado sob várias óticas e sob múltiplas perspectivas. Questões envoltas em tabus e preconceitos são difíceis de lidar devido à discriminação, dependendo da intencionalidade do ato de abortar ${ }^{(2)}$.

No Brasil, o aborto é criminalizado, somente sendo legalizado Quando há risco para a mãe ou em caso de estupro. A legislação do aborto tem sido questionada, pois calcula-se Que ocorram I,4 milhões de abortos clandestinos anualmente.

Eventos estressores são eventos traumáticos Que aparecem sem serem usualmente antecipadas e Que podem induzir a transtornos psicopatológicos ${ }^{(3)}$.

A depressão é a doença Que mais aumenta no mundo, sendo provavelmente responsável por mais de 8 mil suicídios por ano. É o distúrbio psieuiátrico mais comum na prática clínica, afetando $25 \%$ dos adultos $^{(4)}$.

O diagnóstico de depressão leva em conta Que devem estar presente cinco ou mais sintomas como fadiga, alteração de humor, desânimo, insônia e alteração do apetite, por duas ou mais semanas. Além disso, o paciente refere a presença de sintomas diários como sentimento de inutilidade ou culpa excessiva ou inadequada (podendo ser delírio), não meramente auto-recriminação ou culpa por estar doente; fadiga; agitação ou retardo psicomotor; hipersonia ou insônia; ganho ou perda significativa de peso sem estar fazendo nenhuma dieta (mudança de 5\%) e diferença no apetite; interesse diminuído para atividades; humor deprimido; capacidade diminuída de concentrar-se ou tomar decisões e pensamentos de morte ${ }^{(5)}$.

Resiliência é a capacidade de um indivíduo para responder de forma mais consistente aos desafios e dificuldades, reagir com flexibilidade e capacidade de recuperação diante desses desafios ou circunstâncias desfavoráveis, tendo uma atitude otimista, positiva e perseverante e mantendo equilíbrio ${ }^{(6)}$. Pessoas resilientes respondem melhor aos desafios e situações de acordo com sua dinâmica interna e externa com respostas diante de uma situação nova ${ }^{(7)}$.

Os fatores de proteção incluem atividade, autonomia, orientação social, auto-estima, coesão familiar, ausência de grandes conflitos, inteligência, senso de humor, empatia, recursos financeiros, apoio social e recursos individuais ${ }^{(8)}$.

Considerando o aborto e a depressão como problemas de saúde Que necessitam ampla atenção e cuidado, as intervenções de enfermagem são muito importantes no conjunto de ações com vistas à assistência integral identificando fatores de risco e proteção.

\section{OBJETIVO}

Identificar fatores de risco e de proteção para ocorrência de depressão em mulheres, em decorrência de abortamento.

\section{MÉTODO}

Pela natureza desta investigação, a abordagem Qualitativa, uma vez Que a atenção está centrada na pessoa, com a finalidade de compreender o fenômeno por ela vivenciado.

Este estudo foi realizado em duas enfermarias do Hospital das Clínicas de Ribeirão Preto - Unidade de Emergência com aprovação do Comitê de Ética do HCRP - USP.

Foram convidadas a participar da pesquisa, 13 mulheres após 20 horas de internação, considerando Que a média de permanência das internações de abortos, é de um a três dias. A inclusão das mulheres como sujeitos deste estudo ocorreu, independente da faixa etária e da etiologia. Após a concordância das mesmas em participar das entrevistas e após assinatura do termo de consentimento livre e esclarecido.

Garantiu-se, aos sujeitos, com a apresentação formal da enfermeira, o motivo do estudo e a garantia do sigilo.

Entrevista com roteiro Que abordava aspectos de identificação pessoal e sócio demográfica dos sujeitos. As Questões sobre o aborto focalizavam o cuidado de enfermagem aos olhos dessas mulheres com uma pergunta: Como você reconhece o cuidado de enfermagem Que está recebendo? Você pode descrever para mim?

Foram realizadas entrevistas individuais. Para as mulheres que consentiram foi usado um gravador, cujo objetivo foi registrar suas falas com maior fidedignidade, permitindo à pesquisadora observar e anotar linguagem gestual e expressões faciais Que reforçavam os conteúdos dos discursos. O número de mulheres entrevistadas foi determinado pela exaustão das falas registradas nas entrevistas.

Inicialmente, foi feita uma análise global desses dados. Neste momento, lançou-se aos mesmos dados, novo olhar sob a perspectiva da resiliência e reavaliados os dados.

Para analisar o conteúdo vivenciado pelas mulheres realizou-se leitura atentiva dos treze depoimentos. Voltou-se o olhar para os fatores de risco de proteção e de risco. Destacou-se trechos significativos, mantendo-os como foram expressos pelas mulheres. Em seQüência, buscou-se a análise das falas dos sujeitos com base nas publicações do tema.

\section{RESULTADOS}

\section{Perfil das mulheres estudadas}

Durante o encontro com as mulheres, elas falaram sobre suas vidas. Conforme apresentado no Quadro I, vale ressaltar Que as suas idades situavam-se entre 20 a 45 anos. Cinco dessas mulheres relataram ser solteiras, três casadas e cinco amasiadas, eram três analfabetas, três com primeiro grau completo e sete com segundo grau completo. A renda familiar mensal variou de $\mathrm{R} \$ 250,00$ a $\mathrm{R} \$$ 3.000,00. Quanto à ocupação: uma era estudante, três do lar, duas desempregadas, Quatro domésticas, duas balconistas e uma funcionária pública. Onze delas residiam em Ribeirão Preto e as outras em cidades da região.

Dentre as treze, três relataram ser a primeira vez Que engravidaram (primigestas) e, para as outras, o número de filhos variou de um a Quatro. A idade gestacional variou de 9 a 22 semanas. Três revelaram já terem passado pela situação de abortamento, anteriormente. Dessas mulheres, apenas duas haviam planejado a gravidez. Quanto ao uso de métodos contraceptivos, oito revelaram não fazer uso de nenhum tipo de método, três estavam tomando pílula, mas haviam interrompido seu uso (para melhora dos efeitos colaterais); uma esQueceu alguns dias; outra 


\begin{tabular}{|c|c|c|c|c|c|c|c|c|c|}
\hline Idade & $\begin{array}{c}\text { Estado } \\
\text { Civil }\end{array}$ & $\begin{array}{c}\text { Idade } \\
\text { gestacional }\end{array}$ & $\begin{array}{l}\text { Tipo de } \\
\text { aborto }\end{array}$ & $\begin{array}{l}\text { Gestação Parto } \\
\text { Aborto (G P A) }\end{array}$ & Contraceptivo & $\begin{array}{l}\text { Relação } \\
\text { conjugal }\end{array}$ & $\begin{array}{c}\text { Renda } \\
\text { familiar R\$ }\end{array}$ & Ocupação & $\begin{array}{l}\text { Plano de } \\
\text { gravidez }\end{array}$ \\
\hline 31 & solteira & $\begin{array}{l}2 \text { I sem I } \\
\text { dia }\end{array}$ & Incompleto & $G_{3} P_{1} A_{2}$ & pílula & ótima & 250 & doméstica & não \\
\hline 28 & amasiada & $22 \mathrm{sem}$ & Feto morto & $G_{5} P_{4} A_{1}$ & & ótima & 300 & do lar & $\operatorname{sim}$ \\
\hline 23 & casada & $\begin{array}{l}\text { I4 sem I } \\
\text { dia }\end{array}$ & Infectado/retido & $G_{2} P_{1} A_{I}$ & & bom & 700 & doméstica & não \\
\hline 21 & amasiada & 9 sem & Incompleto & $G_{1} P_{0} A_{I}$ & & ótima & 1500 & do lar & não \\
\hline 30 & amasiada & $\begin{array}{l}\text { I I sem } 3 \\
\text { dias }\end{array}$ & Infectado & $\mathrm{G}_{4} \mathrm{P}_{3} \mathrm{~A}_{\mathrm{l}}$ & & bom & 900 & desemp. & não \\
\hline 20 & solteira & 22 semanas & Incompleto & $G_{2} P_{1} A_{1}$ & & bom & 600 & desemp & não \\
\hline 45 & desquitada & $\begin{array}{c}15 \text { sem } 2 \\
\text { dias }\end{array}$ & Inevitável & $G_{1} P_{0} A_{1}$ & & ótima & 1300 & $\begin{array}{c}\text { funcionária } \\
\text { publica }\end{array}$ & não \\
\hline 25 & casada & $\begin{array}{c}10 \text { sem } 4 \\
\text { dias }\end{array}$ & Incompleto & $G_{1} P_{0} A_{I}$ & & ótima & 3000 & vendedora & não \\
\hline 27 & solteira & 10 sem & Incompleto & $\mathrm{G}_{4} \mathrm{P}_{2} \mathrm{~A}_{2}$ & & ótima & 600 & do lar & não \\
\hline 34 & solteira & $\begin{array}{l}19 \text { sem e } 2 \\
\text { dias }\end{array}$ & Incompleto & $G_{3} P_{2} A_{I}$ & condon & bom & 300 & doméstica & não \\
\hline 28 & casada & $21 \mathrm{sem}$ & Incompleto & $G_{3} P_{2} A_{1}$ & & bom & 500 & doméstica & $\operatorname{sim}$ \\
\hline 21 & solteira & $15 \mathrm{sem}$ & Incompleto & $G_{2} P_{1} A_{I}$ & & ruim & 400 & balconista & não \\
\hline 26 & amasiada & 22 sem & Incompleto & $\mathrm{G}_{4} \mathrm{P}_{2} \mathrm{~A}_{2}$ & & bom & 750 & do lar & não \\
\hline
\end{tabular}

\section{Quadro I: Distribuição das mulheres entrevistadas segundo características sócio-demográficas e obstétricas. Ribeirão} Preto, 2008.

relatou Que o condon estourou.

Para garantir e preservar o anonimato, as mulheres foram identificadas por nomes fictícios.

\section{Fatores de risco e de proteção para a ocorrência de depressão em abortamento}

Pelas discussões das mulheres em situação de abortamento, os fatores de risco estão associados à precárias condições sócioeconômicas e afetivas, uso de drogas e álcool, prostituição, local de moradia, falta de apoio social e familiar, violência doméstica. Além disso, existe resistência ao uso de contraceptivos.

Observou-se que as mais jovens Querem adiar e as mais velhas ou já tem filho ou não têm condições econômicas e estruturais favoráveis à criação dos filhos.

Algumas falas evidenciam a assimetria de gênero levando à gravidez indesejada:

"Sabe, homem não entende, às vezes não Quer usar nenhum método...ou te força...eh um pouco de machismo sabe? Lá onde eu moro, as mulheres, são muito submissas ao homem, porQue não tem independência sabe?

...se a gente não cede, a gente não gosta e não faz papel de esposa ou mulher e eles procura na rua, então tem que fazer do jeito que eles querem, a hora Que eles querem e a responsabilidade é só nossa" (9)

Compreende-se por esses discursos a relação de assimetria de gênero e falta de negociação no exercício da sexualidade e na autonomia para tomada de decisão bem como falta de diálogo Que permeia as relações conjugais. Essas mulheres submetem a relações sexuais e sociais contrariando sua vontade e decisão pessoal.

$\mathrm{O}$ aborto pode parecer decisão individual, mas envolve uma série de circunstâncias interligadas à Qualidade e à perspectiva do relacionamento conjugal, dos projetos de vida, das pressões familiares e sociais vividas. A vida afetiva tem um papel importante como motivador da decisão de abortar ${ }^{(9)}$.

A natureza frágil dos relacionamentos afetivo-sexuais Que mantém com seus parceiros, as relações conjugais e também o sofrimento com a ausência, a incompreensão e o descaso do parceiro também são situações Que podem propiciar a ocorrência do aborto e o sofrimento psíquico como mostra a fala abaixo:

\section{“Que nem, se a gente não cede a gente até apanha” (8)}

O sofrimento psicossocial gerado pela falta de suporte do parceiro, seu descompromisso com a gestação e a falta de suporte social tem sido a tônica de muitas situações Que têm na sua terminalidade o aborto e mostram Que, na sociedade atual ainda a responsabilidade feminina sobre a gravidez e o aborto.

O papel do homem foi deixado de lado no estudo da prática da ginecologia e obstetrícia. Entretanto é preciso estimular os homens a não serem violentos e Que aprendam o exercício do direito do casal para a tomada de decisões. A reeducação da masculinidade promove para uma conduta sexual adeeuada; segura e participativa juntamente com a mulher ${ }^{(10)}$

Outros discursos mostram a dificuldade no uso de métodos contraceptivos, a resistência, a falta de informações sobre estes e 
seus possíveis efeitos colaterais:

“Não, eu nunca esqueci. Esses remédio de posto eu acho que é furada, não adianta nada, eu tomei e engravidei, como é isso? Eu Quero agora tomar injeção sabe?" (1)

"pra gente sabe se pergunta, as vezes tá com alguma pergunta pra fazer, direcioná, sabe pra Quem Que pergunta, pra Quem fazer a pergunta. Até também a gente não sabe Quem sabe o Que? Né?" (6)

“...se eu nunca tiver uma orientação das pessoas que é profissional o que que vai acontecer? Aborta de novo, fazer loucura de novo" (9)

“...eu só Queria também fazer uma laqueadura, porque eu não Quero mais ter filho, já tenho dois e não tenho condições...não posso com pílula....Queria muito sabe? Não sei como fazer, com Quem fala...com Quem eu falo? Tem como eu fazer aQui? AQui mesmo? Tem como? Quero muito sabe disso..." (9)

Estes discursos mostram a falta de informações e de orientações. É possível reconhecer Que as mulheres sentem necessidade de orientação e informações sobre contracepção, sexo seguro, pois apesar destes assuntos serem divulgados através da mídia e nos serviços de saúde, há outros fatores Que interagem nas condições de vida dessas mulheres. Mulheres atendidas pelo Sistema Único de Saúde (SUS), em hospital público, têm um contexto geralmente de dependência afetiva e financeira do parceiro. Muitas vezes, este fato impede de desenvolver "empowerment", o Que se mostra também na sua relação com os profissionais de enfermagem ${ }^{(9)}$. Elas esperam, nesses momentos de crise em suas vidas, serem cuidadas e resolver todos os problemas Que lhe parece prioritários tais como suas dificuldades em fazer um planejamento familiar e suas dificuldade no relacionamento conjugal. Observa-se estes discursos:

"Eu sei o valor que é ter um filho. Apesar de que não foi planejado, ele era aceito, mas não era uma boa hora porQue é difícil criar um filho né? as coisas estão difíceis tudo..." (3)

"Único filho que eu tenho, mas eu não casei não, no papel não. O meu primeiro marido, eu vivi cinco anos, amiguei né? Aí eu separei, fiquei quase um ano separada, foi Quando eu conheci o pai desse que ía vim. Mas também já terminamos, faz três meses". Já é difícil criar um filho ainda sem apoio (6)

Esse discurso evidencia a importância do planejamento da gravidez para essas mulheres. Entretanto, ressaltam não apenas as condições materiais para a concretização da maternidade. Outros aspectos como a participação do parceiro, o apoio e a afetividade relacionados à gestação e o cuidado com os filhos também aparecem.

Estudo realizado com profissionais de saúde, aponta motivos Que levariam uma mulher a abortar são: a Questão econômica; a irresponsabilidade da mulher; a gravidez resultante de relacionamento extraconjugal; a rejeição de suas famílias; a ausência de informação para previner uma gravidez indesejada; a gravidez na adolescência; o abandono do namorado e a conseQüente rejeição do feto; o número de filhos; não aceitação da gravidez pelo marido; a Questão das relações sexuais precoces e desprotegidas; a promiscuidade; a falta de fiscalização pelas autoridades. Esses fatores não devem ser considerados como motivos e sim como condições facilitadoras para a ocorrência do abortamento(ll).

O contexto de vida das mulheres, sujeitos deste estudo, apontaram para situações Que mostraram Que o cuidado pessoal nem sempre é incorporado por ela. A gravidez não planejada e o sofrimento resultantes podem levar à concretização do ato do abortamento. As falas abaixo trouxeram à tona situações vividas nestas circunstâncias:

"Que nem eu tava de cinco meses, eu acho, eu e o meu namorado, tava junto há um ano. De três meses pra cá, ele não me procurou mais, sumi.Pra mim foi sofrimento de mais, né? Nós era amigado também. Sabe então pra mim foi tudo de uma vez, estou sem emprego, parei de estudá, foi separação dele, daí um pouco minha mãe faleceu faz dois meses e agora a perda do nenê. Tudo de uma vez. (olhos com lágrimas). Eu acho que todo esse sofrimento teve influência na perda do nenê. PorQue tudo isso é sofrimento, e a gente grávida, não pode passa nervoso, tem que vive o melhor possível né? Então...acho que influenciou na perda, muito difícil". (6)

"E depois também essas coisas que aconteceram né? morte da mãe e separação do meu namorado, tudo né? Então eu me senti um pouco culpada, tudo isso é sofrimento né? Acho que parece que o nenê senti que a gente não tá bem e até desisti de vim “(6)

"PorQue se acontece isso de abortá sempre tem um porQue né? sempre, sempre tem um porque...ou perdeu mesmo sem mexer, sem fazer nada, ou provocou e se provocou tem um porque, sempre tem um porQue...vai ver a vida dessa pessoa, vai ver o Que essa pessoa passa....vai lá ver....as vezes também mata por amor, porQue sabe Que não tem condições de dar amor, carinho, escola e dinheiro" (9)

"Eu sou muito nova, tenho muita coisa ainda pela frente, pra viver sabe? Ter filho agora? Estudo, trabalho... uma vida" (6.)

Diferentes situações conferem especificidades diante da experiência de abortamento, como idade, presença ou não do parceiro, condições de moradia, fatores sócio-econômicos, religião, distância do marido Que trabalha fora, desejo ou não de ter filho, aceitação do marido e aceitação da família ${ }^{(9)}$.

Esses relatos apontam para a importância da compreensão da situação de abortamento, analisando o contexto sócio-econômico e afetivo em Que se encontram, sua história conjugal e de vida para a realização do cuidado à essas mulheres e os riscos para a integridade de sua saúde mental.

Outros aspectos como a participação do parceiro, o apoio e a afetividade relacionados à gestação e o cuidado com os filhos também aparecem.

"Foi triste, é difícil. Eu acho assim, sabe, é importante a gente 
ter apoio...." (8)

"Agora essa vida de..boate essas coisa fui eu, eu que escolhi...é lógico que não é assim, também...a gente procura uma coisa melhor e não acha.....eu era ...não conseguia enxergar...as besteira....não conseguia vê isso...e minha mãe...minha mãe é faxineira sabe? De hospital...e sabe, mesmo com tudo que eu já aprontei pra ela, ela nunca, nunca, nunca me desprezou, me maltratou....me marginalizou sabe? Sabe como que eu consegue saí da vida que eu tinha, com amor....saí das droga, saí da prostituição....porQue eu tive apoio de certas pessoas.....agora pergunta se eu lembro o nome de pessoas Que me maltrataram? Não.... essas eu faço Questão de esQuecer, mas eu guardo muito bem os nomes das pessoas que me ajudaram a sair disso tudo, me levantaram, me falaram o Que era a vida....me ensinaram, me orientaram...essas sim me marcaram...., porque a gente aprende...é só ensina...mas até eu chega aí...eu sofri...sofri desprezo, humilhação tudo...." (9)

Há relatos Que mostram a dificuldade de enfrentamento após a situação, mostrando a possibilidade de afetar a integridade mental:

"Sabe, depois do aborto, a gente sabe Que tem muito problemas da cabeça como a gente tem pesadelo, sentimento ruim e fica muito triste, desanimado...acho que mesmo Quem perdeu porque Quis, imagine Que perdeu Querendo a gravidez" (8)

Eventos agudos podem ser infinitamente mais desastrosos do Que condições crônicas a Que o indivíduo já está habituado ${ }^{(12)}$. No entanto, pessoas expostas à adversidade crônica têm mais dificuldade em lidar com eventos de vida agudos. Os diferentes níveis individuais de tolerância ao estresse também oscilam conforme a situação enfrentada ${ }^{(13)}$.

Estudos epidemiológicos dos transtornos psiQuiátricos na mulher mostram Que a conscientização de Que estes transtornos são um sério problema de saúde pública é relativamente recente, especialmente após uma publicação da OMS. A pesquisa como medida uma combinação do número de anos vividos com incapacidade e conseQuente deteriorização da Qualidade de vida; mostrou a intensa diferença de gêneros na incidência e curso de transtornos mentais, assim como na apresentação clínica e na resposta terapêutica ${ }^{(14)}$.

A diferença entre a prevalência de depressão em mulheres e em homens é observada em várias regiões do mundo e esta razão tem variado entre 1,5 e 3,0, com média de duas mulheres para cada homem. Além das especificidades biológicas, há também os fatores como pressões sociais, estresse crônico e baixo nível de satisfação associado ao desempenho de papéis tradicionalmente femininos, ou pela forma diferencial entre gêneros de lidar com problemas e buscar soluções. Outro argumento é Que as mulheres teriam maior facilidade de identificar sintomas, admitir Que estão deprimidas e de buscar ajuda Que os homens ${ }^{(14)}$.

Fatores de risco associados à depressão têm sido identificados, incluindo história familiar, adversidade na infância, aspectos associados à personalidade, isolamento social e exposição a experiências estressantes. Estudos mostram também mulheres apresentando maiores taxas de ansiedade associada à depressão e homens mostrando maior abuso de álcool e transtorno de conduta $^{(14)}$.

Fatores de risco psicológicos Que precedem o aborto, bem como os efeitos prejudiciais psicológicos, físicos e sociais não têm sido considerados como relevantes ${ }^{(15)}$.

As mulheres sofrem de Síndrome Pós-aborto, experimentando o "luto incluso", uma dor Que na maioria das vezes é negada mesmo Quando uma morte real ocorreu. Por causa desta negação, o luto "não pode" praticamente existir. Mesmo assim, a dor da perda ainda está presente e muitas têm "flashbacks" da experiência do aborto e inclusive pesadelos sobre o bebê e até mesmo sofrimento no aniversário da morte ${ }^{(5)}$.

Os efeitos psicológicos mais comuns da situação de aborto são sentimentos de culpa, impulsos suicidas, pesar/abandono, perda da fé, baixa estima pessoal, preocupação com a morte, hostilidade e raiva, desespero/desamparo, desejo de lembrar a data de nascimento, alto interesse em bebês, frustração do instinto maternal, mágoa e sentimentos ruins em relação às pessoas ligadas a situação, desejo de terminar o relacionamento com o parceiro, perda de interesse sexual, frigidez, incapacidade de se perdoar, nervosismos, pesadelos, tonturas, tremores, sentimento de estar sendo explorada, dentre outros ${ }^{(15)}$.

O aborto, no caso de ser provocado, causa ansiedade, depressão, culpa e vergonha por até cinco anos. Os abortos naturais causam depressão e ansiedade apenas durante os seis primeiros meses depois da perda do bebê, encuanto que os abortos provocados têm um efeito mais negativo psicologicamente e mais duradouro ${ }^{(16)}$. Esta pesquisa foi duramente criticada por grupos pró-aborto Que afirmam não haver evidências concretas para demonstrar Que este tipo de decisão está diretamente relacionada a traumas psicológicos. Questiona-se o fato destas mulheres apresentarem, anteriormente, algum distúrbio psicológico.

A depressão é um efeito natural do aborto e pode aparecer anos depois. A depressão causada por um aborto, independente da causa ou das situações envolvidas, é uma condição oculta e ignorada, porém necessária à prevenção e o tratamento ${ }^{(17)}$. Os autores acrescentam Que muitas mulheres vão a tratamento para depressão, ansiedade, vícios, mas não compreendem as raízes de sua enfermidade. Muitas vezes são "narcotizadas" e "nunca lhes é dado o diagnóstico nem se direciona para trata-las no caminho da cura e da recuperação". Os autores afirmam Que a lembrança e os sentimentos não resolvidos sobre o aborto convertem-se em fontes de pressão Que podem surgir anos depois em formas inesperadas. As emoções não resolvidas demandarão atenção cedo ou tarde, com freqüência através do desenvolvimento de perturbações emocionais ou de comportamento ${ }^{(17)}$.

As mulheres revelam também problemas com drogas, associados com o ato de abortar e a promiscuidade:

"Que eu já tive problema né? com overdose, já tive problema com parada cardíaca. Então isso tudo preencheu minha cabeça, mas não....elas me deram força. Eu tive problema sério com droga, muita droga...mas só que de repente pra poder disfarçar ela bébe, pra pode disfarçar, esquece da vida, dos problemas, pra passa o sofrimento...hoje eu vejo assim, as vezes a gente não é forte o suficiente pra suportar certas coisa, problema e a gente diante daquilo fica cega, faz loucura mesmo e não tem 
apoio de ninguém...e isso é pior ainda, porque aí que você se vê sozinha, aí você pensa não tenho nada a perdê mesmo...ninguém me valorizou....hoje eu sei Que é a gente Que tem Que se valoriza primeiro, mas antes eu não. Eu penso assim. Eu pelo menos penso assim né?....Muitas pessoas não conseguem enxerga isso e ser tratada como eu fui da vez que eu tirei mesmo o meu filho, eu provoquei com sondinha o aborto, a gente sofre mais ainda, mas não foi com o Que eles me fizeram Que eu aprendi não....foi a vida Que me ensinou e as poucas pessoas Que eu pude contar, pude falar a verdade e me estenderam a mão, uma delas foi aQuela enfermeira Que eu te falei.Igual...já Que eu comecei a falar eu vou falar mesmo sabe? Por exemplo a lei, a lei proibe o aborto, mas ele acontece, e aí? Ele acontece mesmo....e a gente tem Que ir pro hospital...como Que fica isso? Eu sei Que isso não devia acontecer...igual comigo nunca mais...sabe? eu acho Que é tão bom você poder falar o Que sente, o que deve...sabe?" (1)

Problemas com drogas e álcool. De acordo com essa fala, observa-se mais uma vez a importância do contexto da vida dessas mulheres, problemas como drogas, prostituição e da consciência delas diante do ato de abortar, em um momento de desespero.

As mulheres apresentam maiores taxas de prevalência de transtorno de ansiedade e de humor do Que os homens. A vulnerabilidade é marcante para sintomas ansiosos e depressivos, especialmente associados ao período reprodutivo ${ }^{(18)}$.

\section{Fatores de proteção}

Os fatores de proteção ou mecanismos de proteção Que um indivíduo dispõe internamente ou capta do meio em Que vive são considerados elementos cruciais para medir a resiliência.

Os processos de proteção têm a característica essencial de provocar uma modificação da resposta do indivíduo aos processos de risco, possuindo funções como reduzir o impactos dos riscos, fato Que altera a exposição da pessoa à situação adversa; reduzir as reações negativas em cadeia Que seguem a exposição do indivíduo à situação de risco; estabelecer e manter a auto-estima e autoeficácia , através de estabelecimento de relações de apego seguras e o cumprimento de tarefas com sucesso e criar oportunidades para reverter os efeitos do estresse $\mathrm{e}^{(8)}$.

A resiliência é o produto final da combinação e acúmulo dos fatores de proteção $\mathrm{O}^{(19)}$.

Pelas falas das mulheres deste estudo, condições sócioeconômicas favoráveis à criação dos filhos, sem passar necessidades básicas, o apoio familiar e social são importantes. Além do aspecto afetivo relacional especialmente com o companheiro, a profissão Que exerce.

As falas das mulheres revelaram Que o apoio, nesse momento, é imprescindível juntamente com a situação de apoio financeiro ou ter uma profissão Que possa dar suporte ao nascimento da criança:

"Meu pai trouxe um enxoval inteiro de nenê, eu ainda abri, arrumei as roupas no guarda-roupa. Apoio da família, por enQuanto eu só vi meu pai..." (6)

"Quando a gente tem família apoiando, a gente se sente mais forte. Quando tem um parceiro, tudo isso influencia e muito. A gente sabe Que mesmo não tendo profissão, tem como arcar com o nascimento" (4)

"Ele chegou pra mim e falou: aconteceu, vamos para a frente. Se eu perdi foi mesmo porque tinha Quer ser, mas Quando e assim, acho Que a gente sofre menos...Eu sou independente, tenho minha profissão, minha vida, eu tenho poder de decisão...no aspecto econômico pelo menos, agora Que o apoio da família e também a presença de um pai é também importante, é todo um conjunto" (4)

Diante dos fatores potencialmente geradores de desequilíbrio para cada indivíduo, os mecanismos de proteção são tomadas como o ponto chave necessário para o restabelecimento do equilíbrio perdido e demonstração de competência apesar da adversidade ${ }^{(12)}$.

O apoio social têm Quatro dimensões: o emocional (apoio recebido através da confiança, da disponibilidade em ouvir, compartilhar preocupações/medo e compreender seus problemas), de informação (através de sugestões, bons conselhos, informação e conselhos), afetiva (demonstração de afeto e amor, dar abraço) e de interação positiva (diversão juntos, relaxar, fazer coisas agradáveis e distrair a cabeça). O relacionamento com amigos e parentes, isto é, uma rede social ${ }^{(20)}$.

“Tive amigos que me apoiaram Que me entenderam" (4)

A auto-estima é outro fator protetor importante, pois esta designa o grau de consideração ou respeito Que os indivíduos têm em relação a si mesmo e é uma medida do valor Que eles atribuem a suas capacidades e seus julgamentos.

Os indivíduos têm de conseguir uma auto-estima positiva para poderem obter a auto-realização. No dia-a-dia, o valor de eu do indivíduo é posto a prova por modificações no ambiente. Com um valor do eu positivo os indivíduos conseguem adaptar-se com êxito às exigências associadas às crises $^{(20)}$.

"Agora eu sei que é a gente que tem Que se gosta primeiro, se valorizar. E isso é tudo" (9)

Esse discurso mostra a importância de informações e orientações como fatores protetores para o cuidado integral a mulher em abortamento:

"A gente tem informações, a gente se sente mais preparada para fazer nossas decisões" (4)

Apesar de mostrar Que esta situação se mostra propícia para a orientação sobre métodos contraceptivos e orientações sobre resistência aos métodos, e a importância de encaminhar essas mulheres, ou seja, a referência e a contra-referência, muitas profissionais têm dificuldade em realizar essa tarefa. Ainda há muito preconceito entre os profissionais com o diagnóstico de abortamento $^{(21)}$

Por volta do início do século XIX era clara e explícita a diferença na assistência ${ }^{(22)}$. Ao se descobrir o ato de abortar, se negava a administração de anestésicos a essas mulheres. Na curetagem uterina, a espera para atendimento era maior, o descaso era 
alarmante, punindo-as na dor com uma vingança pelo ato assassino cometido por elas.

Aspectos como sentimentos e emoções Que muitos profissionais relutam em levar adiante podem, paradoxalmente, torná-los mais fortalecidos e menos vulneráveis. Acrescenta que levar a dimensão pessoal para a prática nos serviços de saúde não é tarefa fácil, pois exige preparo e um certo treino, já Que geralmente, somos impelidos a perpetuar atitudes habituais Que excluem os sentimentos do profissional $^{(23)}$

A importância do apoio profissional é relatado nos discursos destas mulheres:

"É tão bom receber o apoio da equipe, a gente sofre menos" (4)

Os profissionais cuidar dessas mulheres não devem se nortear por algum julgamento preconceituoso. É importante o respeito ao silêncio das mulheres nesse momento, pois o fato de algumas delas não se manifestarem, visivelmente, com choros ou expressões de tristeza, não significa Que a situação de abortamento não se apresenta como uma situação de dor e, nesse sentido, observa-se um alerta para a importância do silêncio na linguagem humana ${ }^{(9)}$.

\section{CONCLUSÕES}

Na assistência à mulher em situação de abortamento predomina o cuidado centrado no atendimento às necessidades físicas. Tal prática pode ser decorrente de Que preparados para o evento da vida e para sua preservação sob as condições mais saudáveis possíveis, os profissionais da saúde euando presenciam a morte inelutável, sentem-se despreparados e constrangidos.

Ao buscar identificar fatores de risco para a depressão e de proteção à saúde da mulher em abortamento foram destacados elementos Que poderão dar subsídios, promoção de sua saúde mental.

É preciso transpor o modelo clínico de saúde facilitando o acesso à informação e ao cuidado específico, respeitando sua autonomia e sua individualidade.

Para avançar no cuidado é preciso compreender a mulher, não apenas fisicamente, mas como ser humano Que vivencia tal situação e sem dúvida, experimenta sofrimento e sentimentos dolorosos.

Este estudo gera reflexões e possibilidades de ser repensado o aborto e os fatores de risco e de proteção, buscando um olhar para outras dimensões na assistência, na integralidade do cuidado de enfermagem.

\section{REFERÊNCIAS}

I. Ministério da Saúde (BR). Secretaria de Políticas de Saúde. Área técnica de Saúde da Mulher. Parto, aborto e puerpério: assistência humanizada à mulher. Brasília: Ministério da Saúde; 2001 .

2. Longo RT. Estudo sobre aborto - uma primeira aproximação. In: $48^{\circ}$. Congresso Brasileiro de Enfermagem. Ribeirão Preto (SP), Brasil. Ribeirão Preto: ABEn-SP; 1997.

3. Vaz Serra A. O stress na vida de todos os dias. Coimbra, Gráfica de Coimbra; 1999.

4. Organização Panamericana de Saúde. Programa de Salud Mental, División de Promoción de Salud. Modelo para la capacitación de la enfermera general en al identificación y manejo de los trantornos afectivos. Genebra: OMS; 1999.

5. Manual diagnóstico e estatístico de transtornos mentais. Porto Alegre: Artes Médicas; 1994.

6. Placco VMNS. Resiliência e educação. São Paulo: Cortez; 2001 .

7. Simões CM. Desenvolvimento do professor e construção do conhecimento pedagógico. Aveiro: Fundação Jacinto de Magalhães; 1996.

8. Rutter M. Maternal deprivation reassessed. Harmondsworth: Penguin; 1981.

9. Mariutti MG; Boemer MR. A mulher em Situação de Abortamento: um enfoque existencial. Rev Esc Enferm USP 2003; 37(2): 59-71.

10. Mariscal JDO. Direitos sexuais e reprodutivos das mulheres. CREMESP 200I; 4(5): 2-9.

I I. Espírito Santo PSMF. Aborto - percepção de profissionais de emergência de Ribeirão Preto. [dissertação]. Ribeirão Preto: Faculdade de Medicina, Universidade de São Paulo; 2003.

12. Garmezy N. Resiliency and vulnerability to adverse developmental outcomes associated with poverty. Am Behavioral Scientist 1991; 34(4): 416-30.

13. Savoia MG. Escalas de eventos vitais e de estratégias de enfrentamento (coping). Rev Psie Clín 1999; 26(2): 57-67.

14. Justo LP, Calil HM. Depressão - o mesmo acometimento para homens e mulheres? Rev Psie Clín 2006; 33(2); 74-9.

15. Pavone FA. Efeitos do aborto - Priests for life. [citado em: 2006 ago 12]. Disponível em: http:// www.ansa.it/ansalatina/ notizie/rubriche/

16. Broen AN, Moum T, Bodtker AS, Ekeberg O. The course of mental after miscarriage and Induced abortion: a longitudinal, five-year follow-up study. BMC Med 2005; 3: 18.

17. Klier CM, Geller PA; Neugebauer R: Minor depressive disorder in context of miscarriage. I Affect Disord 2000; 59: 13-2 I.

18. Andrade LHSG, Viana MC, Silveira C M. Epidemiologia dos transtornos psieuiátricos na mulher. Rev Psie Clín 2006; 33(2); 43-54.

19. Tavares I, organizador. Resiliência e educação São Paulo: Cortez; 2001 .

20. Chor D, Grip RH, Lopes CS \& Farstein E. Medidas de rede e apoio social no estudo pró-Saúde: pré-testes e estudo piloto. Cad Saúde Pública 2001; 17(4): 887-96.

21. Mariutti MG, Almeida AM, Panobianco MS. Nursing care according to women in abortin situacions. Rev Latino-am Enfermagem 2007; 15(1): 20-6.

22. Rezende I. Obstetrícia. 3 $3^{\text {a. }}$ ed. Rio de Janeiro: Guanabara Koogan; 1974.

23. Remen RN. O paciente como ser humano. São Paulo: Summus; 1993 